\section{Underground mysteries}

\author{
Brian Bertram
}

The Biology of the Naked Mole-Rat. Edited by P. W. Sherman, J. Jarvis and A. Alexander. Princeton University Press: 1991. Pp. 529. \$65, £40 (hbk); $\$ 24.95, £ 17.75$ (pbk).

LITTLE volcano-shaped mounds on the dry ground of the horn of Africa are the only signs of an astonishing underground community, which has everything to catch the headlines: slavery, incest, bloody fights, nakedness, faeces-eating, temporary castration and remarkable teamwork. A new book at last brings all these goings-on to the surface. Its title inevitably undersells the variety and fascination that it contains within.

The beasts are unattractive at first sight, but in fact they are scarcely ever seen, which is partly why the intricacies of their social system have only started to be unravelled in recent years.

The book, well-edited by the three principal workers on the species, brings together and summarizes nearly two decades of study by some 22 researchers on the species, both in the wild and in perspex tubes in the laboratory. The extent of cooperation among the molerat people over the years, forsaking temptations to race one another into print, has been highly laudable and productive, matching the marked cooperation exhibited by their subjects.

All sorts of facts are revealed about these most unusual rodents. Naked mole-rats are pinkly naked with miscellaneous whiskers, almost blind and partly poikilothermic (that is, with a lowerable body temperature). They live totally underground, gnawing their way through very hard soil with their incisors, and working cooperatively to kick the huge amounts of soil backwards and eventually to throw it out onto the surface. They live in colonies of about 70 to 80 individuals, which scuttle along in a tunnel system roughly 3 kilometres in extent, and feed on the large underground food stores of arid country plants. There is relatively little genetic variation between colonies and very little within the clearly inbred colonies.

For small mammals (mean weight 34 grammes), they are extraordinarily longlived - at least a dozen years. The gestation period is 2.5 months, compared with 2 weeks for a mouse and 2 months for a cat. The young take a year to reach adult size, which depends on many factors, including the presence of a breeding female. She herself is almost twice the average adult size, and particu- larly elongated.

Naked mole-rats are the most highly social of any species of vertebrate. Only one female in the colony reproduces, and only two or three males. The rest are sterile, their reproductive maturation suppressed by the queen by both chemical and behavioural means. This suppression is lost if the queen is removed or dies, when almost any female has the capacity to compete to replace her.

The queen may retain her reproductive status and monopoly for several years, producing litters of about a dozen young (up to 27 ) every 2.5 to 3 months. Many other colony members help with their upbringing by carrying, retrieving, grooming, bringing back food and providing faeces.

Social living so cooperative that it involves individuals forgoing their own reproduction is termed eusociality; it is known in the colonial bees and wasps, the termites, in some aphids and now in naked mole-rats. Why it should evolve, in any particular case, and in general, is much debated both in this fascinating book and elsewhere.

It is clear that in their present niche and habitat, naked mole-rats can survive only if living socially. They need companions to share in the huge task of burrowing long distances through a hard substrate to find sparsely distributed food; but, once found, the food can feed many individuals. Group defence against predatory snakes is probably essential. A naked mole-rat out of its own tunnel system is likely to be doomed.

The evolution of sterility is a puzzle exactly how does natural selection favour the spread of the trait of not breeding? A satisfying partial solution for workers of social bees and wasps was provided by Bill Hamilton in 1964; he pointed out that those species are haplodiploid, so a (female) worker bee would on average be less closely related to her own offspring than she would be to her monogamous mother's. But naked molerats are diploid like all other mammals, so the key causes must lie elsewhere.

A queen naked mole-rat, surrounded by overlapping generations of her own long-lived offspring, will be more closely related to her own offspring than she would be to the offspring of her daughters, were they to attempt to breed; it would be in her genetic interest, if breeding by the colony is limited, for her to be the breeder. For her daughters, it does not make so much difference, because a worker mole-rat would share half her genetic material with her own daughter, as she does with her younger sisters produced by her monogamous mother. Thus, in any conflict over who should reproduce, there is an asymmetry in the potential benefit. In addition, the confined tunnel network (virtually a one- dimensional habitat) makes it difficult for a subordinate to avoid the influence of a dominant attempting to control her.

In contrast with tidy explanations, the species is highly variable in its behaviour. This excellent and eagerly awaited book provides a gold-mine of fact and theory on which to base the discussions it will surely stimulate.

Brian Bertram is at The Wildfowl and Wetlands Trust, Slimbridge, Gloucester GL2 7BT, $U K$, and was formerly Curator of Mammals at the Zoological Society of London.

\section{Highway codes}

John Armstrong

Intracellular Trafficking of Proteins. Edited by Clifford J. Steer and John A. Hanover. Cambridge University Press: 1991. Pp. 745. £85, $\$ 150$.

PROTEINS find their way into all sorts of places inside and outside cells. From a common origin in the cytoplasm, the different polypeptide constituents of each cellular organelle and compartment are sorted and delivered to their destinations. These processes involved in the traffic of protein constitute one of the most exciting areas of current cell biology: progress can be so rapid that even those within the field have trouble keeping abreast of developments. There is therefore a demand for a volume such as this one. How far does the book meet its publisher's claim of being "essential reading for beginning students as well as for established investigators"?

First, any 'beginning student' who can be persuaded to lift this tome, twohanded, off the library shelf will encounter a conventional format, with no pretensions to the attention-grabbing techniques of modern cell-biology textbooks. The overall structure is the familiar multiauthored one, and sadly the usual criticisms of such volumes apply - a variable quality of writing, overlap of material and long production time. The last is perhaps the most worrying in a fast-moving area; indeed, three of the authors point this out. P. Courtoy, in his contribution on the "dissection of endosomes", comments between gritted teeth that since the article was written in 1988 , several more reviews of the field have appeared, one by himself (although the chapter is still well worth reading). $\mathbf{M}$. Farquhar in her chapter on the Golgi complex concludes philosophically that the pace of change "will render the useful life of this review remarkably short"; but longer, surely, than the production time of the book?

Conventional presentations of the traffic of proteins begin with the birth of the 